\title{
4-year recurrence risk factors after tension-free vaginal tape-obturator as a treatment of stress urinary incontinence
}

\begin{abstract}
Objetive: The objective is to identify factors associated with the risk of recurrence of stress urinary incontinence at 4years, after surgical treatment with transobturator suburethral tape.

Methods: A prospective four-year follow-up observational study (2015-2019, n=341) was performed in women who underwent SUI using the tension-free vaginal tape-obturator. The sample was 71 patients with recurrence of SUI.
\end{abstract}

Statistics: T-Test or U-Mann and ROC for quantitative variables, Chi-Square and OR for qualitative variables.

Results: The frecuency of SUI recidive was $11.27 \%$ (8 patients).

Of all the variables analyzed, they only showed a significant association with the SUI recurrence: age, fetal macrosomia and mixed urinary incontinence.

The frequency of recurrence in case mixed incontinence amounted to $19.5 \%$, if the patient had 1 delivery $>4 \mathrm{~kg}$ to $22 \%$ and if the antecedent was $\geq 2$ macrosomal deliveries it increased up to $50 \%$.

Conclusion: Advanced age, macrosomic delivery and mixed urinary incontinence have shown a significant association with the risk of relapse of SUI after tension-free vaginal tape-obturator at 4 years

Therefore, it would be necessary to inform them of a greater risk of failure in the medium term in the preoperative interview.

Keywords: recurrence, risk factors, stress urinary incontinence
Volume II Issue 6 - 2020

\author{
De Miguel Manso S,',2 García García E,' \\ Gobernado Tejedor JA,' Badillo Bercebal \\ CE,' Viruega Cuaresma D,' González Martín \\ JI' \\ 'Department of Obstetrics and Gynecology,Valladolid \\ University Clinical Hospital, Spain \\ ${ }^{2}$ Faculty of Medicine, University of Valladolid, Spain
}

\begin{abstract}
Correspondence: S De Miguel Manso, Department of Obstetrics and Gynecology, Valladolid University Clinical Hospital, Faculty of Medicine, University of Valladolid, José Velicia Street, Number 7I, 47008-Valladolid, Spain, Tel +34617061826, Email soniadeiguel@yahoo.com
\end{abstract}

Received: November II, 2020 | Published: November 18, 2020
Abbreviations: BMI, body mass index; MUI, mixed urinary incontinence; OR, odds ratio; POP, pelvic organ prolapse; ROC, receiver operating characteristic; SUI, stress urinary incontinence; TO, transobturator bands; TVT, retropubic bands; UDS, urodynamic study

Key message: Stress urinary incontinence can recur so investigate possible risk factors is a priority. Our paper relates recurrence with: advanced age, fetal macrosomia and mixed incontinence.

\section{Introduction}

Stress urinary incontinence (SUI) is defined, according to the ICS (International Continence Society) terminology standardization, as involuntary loss of urine after physical exertion (sport, activity) or after coughing or sneezing. ${ }^{1}$ It is estimated that its prevalence in the female population ranges between 10 and $40 \%{ }^{2}$ This highly variable rate depends on the definition used (if the urine loss is several times a day or a week), on the methodology used for follow-up (revision in consultation, telephone interview or questionnaire by mail) and on the population differences between studies.

Treatment of SUI depends on the degree of severity. Therapy generally begins by changing lifestyle and the rehabilitation of the pelvic floor musculature for at least 3 months. In moderate and severe cases, when these measures have failed, surgical treatment will be indicated, which will depend on the degree and conditions of the patient (suburethral band or bulking agents if there are comorbidities that make surgery impossible). ${ }^{2}$

Rehabilitation of the pelvic floor muscles is effective for the treatment of mild-moderate SUI in the short-medium term and is more effective than the absence of treatment. Nevertheless, it requires persistence and maintaining some training programs that preserve the healing effect. Therefore, a significant number of women will seek other treatment alternatives with a faster cure. ${ }^{3}$

Synthetic suburethral polypropylene tapes are the "gold standard" for the surgical treatment of SUI according to the guidelines of the European Society of Urology (ESU, 2016) ${ }^{4}$ and the position of the European Urogynecological Association (USA, 2017).

Current tension-free vaginal tapes include the retropubic and transobturator pathways.

A systematic review of long-term randomized studies ( $\geq 5$ years) comparing transobturator tapes (TO) versus retropubic tapes (TVT), reveals that they present similar objective cure rates $(64.4 \%$ vs $61.6 \%, \mathrm{OR}=0.87, \mathrm{p}=0.62)$ and similar subjective cure rates $(81.3 \%$ vs $76.5 \%, \mathrm{OR}=0.84, \mathrm{p}=0.58$ ), finding no significant differences in complications. ${ }^{6}$ 
The largest long-term randomized controlled study (9 years, $\mathrm{n}=341$ ) performed with TO (both modalities: in-out and out-in) reveals a stable success rate with transobturator tape after 3 years. The subjective cure at 1,3 and 9years was $80 \%, 73.1 \%$ and $71.6 \%$ respectively. The reduction in the cure rate was significant between the first and ninth year, but not between the first and third year. ${ }^{7,8}$

In 2006, a third generation of suburethral tape, mini-sling or single incision sling emerged in an attempt to reduce the morbidity and invasiveness of transobturator tapes. Studies comparing TO and TVT ${ }^{9}$ techniques versus mini-sling tapes in the short and medium-term show that mini-sling is not inferior to TO and TVT, but a definitive positioning concerning this new generation of suburethral tapes is not possible to establish due to a lack of studies in the long-term.

Therefore, the surgical treatment of SUI with a tension-free vaginal tape is currently performed using the TO pathway, which has shown high cure rates, especially in the short and medium-term, since the long-term studies report highly variable rates, between 43 and $92 \%{ }^{10}$ (Cochrane, 2017).

The decrease in cure rate in the medium and long term means that SUI recurs, and many are the variables that have been studied and that may influence.

The objective of this study is to identify factors associated with the risk of recurrence of SUI after 4years.

\section{Material and methods}

A prospective four-year follow-up observational study (20152019) was performed in women suffering from stress urinary incontinence who underwent treatment using the tension-free vaginal tape-obturator.

All the patients underwent treatment in the Universitary Clinic Hospital of Valladolid and were evaluated at the Pelvic Floor Unit. The main output variable studied was recurrence of stress urinary incontinence (positive cough test with a frequency of at least several times per week) and the follow-up was carried-out after 6 months, 1 , 2, 3 and 4years: over the first 2years it was perfomed in person at the consultation and for the $3^{\text {rd }}$ and the $4^{\text {th }}$ year patients were evaluated by telephone interview. As secondary results, we value possible variables associated with the risk of recurrence and differences in complications between patients with and without recurrence.

Objective cure was evaluated using the cough test in consultation (with a bladder filled with $250-300 \mathrm{ml}$ and checked by ultrasound) and by telephone through an exhaustive anamnesis of SUI symptoms. Subjective cure was evaluated with the PGI (Patient Global Impression of Improvement) scale.

The only exclusion criteria for the insertion of a TO band were being under 18years old and suffering from SUI due to intrinsic sphincter deficiency evaluated by urodynamic study (UDS).

No patient had to be excluded because of these reasons. Therefore, women without taking into account the following criteria were included: body mass index (BMI), previous anti-incontinence surgery, associated pelvic organ prolapse surgery (POP) and symptoms of overactive bladder with or without incontinence.

Anthropometric variables (age, height, weight and BMI), obstetric history (parity, vaginal delivery of fetus $>4 \mathrm{~kg}$, delivery with forceps), comorbidity (AH, respiratory, neurological or psychiatric pathology), concomitant medication (antihypertensive, respiratory, neurological or psychiatric), previous anti-incontinence surgery, type of urinary incontinence (effort, mixed), severity of SUI (Grade I, II, III), type of TO tape (in-out, out-in ), correction of associated POP and type of surgery were studied.

The UDS was only performed in recurrent SUI, when SUI was suspected to be due to intrinsic sphincter deficiency and in complex urine incontinence (UI).

Post-surgical complications were recorded and classified by time periods: immediate ( $<7$ days), intermediate ( $7-30$ days), and late $(>1$ month).

Patients with mixed urinary incontinence (MUI) and/or treatment with anticholinergics, with previous surgeries of SUI and who underwent concomitant POP surgery were also included.

The surgery was performed by 4 gynecologists and the insertion modality, in-out or out-in, depended on the surgeon's preference.

The types of in-out TO tape used were: I-Stop Braun ${ }^{\circledR}$ (B. Braun SA, Barcelona) and TOA ${ }^{\circledR}$ (Presurgy SL adjustable sling, Madrid), and with the out-in needle path Monarc ${ }^{\circledR}$ bands were placed until 2015 (AMS, Inc., Minnetonka, USA).

\section{Estatistical analyses}

The Kolmogorov-Smirnov test was applied for quantitative variables to determine the type of distribution. The T-Student test was used to study quantitative variables with a normal distribution, and the U-Mann-Witney test was used otherwise. The Chi-square test with Yates correction was used to study qualitative variables. In all cases, less than 0.05 was the value taken as statistically significant. For quantitative variables with a statistically significant relationship, a ROC curve was constructed and the area under the curve was calculated, and for qualitative variables the OR was calculated with a $95 \%$ confidence interval. SSPS v. 23 was the stadistic software used.

\section{Ethical approval}

The patients were verbally informed individually, both in consultation and by telephone, that their data will be included in studies on the results of the anti-incontinence bands, if they were satisfied with it. For this purpose, this study was authorized by the ethics and research committee of the eastern health area of Valladolid. With start date of the study 02-13-2015 and approval date 03-18-2016 (Code: FO-P07-12) (Appendice-1).

Informed written consent was obtained from the patients to undergo the surgical intervention, and regarding the degree of satisfaction during the follow-up, the consent was verbal informing them that the data would be treated respectfully and confidentially with the intention of studying the long-term results of the bands.

\section{Results}

The sample was composed of 71 women operated on with tensionfree vaginal tape-obturator and followed during 4 years: 8 women of this sample showed symptomatic relapse of SUI, representing $11.27 \%$ of recurrence. There were no significant differences regarding the type of TO tape placed, either the insertion of the needle from inside to outside or from outside to inside (Table 1). 
Table I Type of transobturator tape

\begin{tabular}{llll}
\hline \multirow{2}{*}{ Type of to tape } & \multicolumn{2}{l}{ Recidive } \\
\cline { 2 - 3 } & No (63) & Yes (8) \\
\hline $\begin{array}{l}\text { Out-In: } \\
\text { Monarc } ®\end{array}$ & 8 & 2 & $0.117 \mathrm{a}$ \\
In-Out: & & & \\
I-Stop® & 47 & 6 & \\
TOA® & 8 & 0 & \\
a Chi-square & & & \\
\hline
\end{tabular}

From all variables analyzed those that showed a significant association with the recurrence of SUI in the univariate analysis were age, a history of fetal macrosomia and suffering from MUI. The most relevant factors studied are shown in Table 2.

From the entire sample, 10 patients had a history of antiincontinence surgery: 6 of them had already another transobturator tape put down and 4 of them had another mini-sling tape put down. These 10 patients were also evaluated with UDS to rule out intrinsic sphincter deficit before vaginal tape-obturator tension-free. Another patient required a UDS for complex urinary symptoms, ruling out sphincter deficiency.

49 women of the sample also underwent a POP surgery in the same procedure. Neither of these 2 variables were related to the risk of recurrence (Table 2).

Table 2 Univariate associations between anthropometric, obstetric, medical variables, type and grade of urinary incontinence, previous surgery for SUI, simultaneous surgery for POP, previous urodinamic study and complications, and the development of relapse of SUI

\begin{tabular}{|c|c|c|c|}
\hline \multirow{2}{*}{ Variable } & \multicolumn{2}{|l|}{ Recidive } & \multirow{2}{*}{$\mathbf{P}$} \\
\hline & No & Yes & \\
\hline Age (70) & $(62)$ & (8) & $<0.008^{\mathrm{a}}$ \\
\hline Median (Range QI-Q3) & $67.00(4 \mid-80)$ & $75.00(64-85)$ & \\
\hline Weight (kg) (68) & $(61)$ & (7) & $0.370^{\mathrm{b}}$ \\
\hline Mean \pm Standard Deviation & $69.79 \pm 11.722$ & $65.57 \pm|1.73|$ & \\
\hline Daily Physical Activity (14) & 14 & 0 & $0.137^{c}$ \\
\hline Parity $(\geq 1)(66)$ & 58 & 8 & $0.099^{a}$ \\
\hline Forceps ( $\geq 1)(4)$ & 4 & 0 & $0.635^{c}$ \\
\hline \multicolumn{4}{|l|}{ Fetal Macrosomy (13) } \\
\hline I delivery $>4 \mathrm{~kg}$ & 7 & 2 & $0.01^{\mathrm{c}}$ \\
\hline$\geq 2$ deliveries $>4 \mathrm{~kg}$ & 2 & 2 & \\
\hline $\mathrm{AH}(35)$ & 30 & 5 & $0.428^{c}$ \\
\hline Respiratory Pathology (4) & 3 & 1 & $0.37 I^{c}$ \\
\hline Psychiatric Pathology (15) & 13 & 2 & $0.776^{c}$ \\
\hline Tobacco $\geq 5$ Per Day (5) & 5 & 0 & $P=0.409^{c}$ \\
\hline Previous MUI (4I) & 33 & 8 & $\mathrm{P}=0.010^{\mathrm{c}}$ \\
\hline \multicolumn{4}{|l|}{ SUI grade: } \\
\hline I (2) & 2 & 0 & \multirow{2}{*}{$0.842^{c}$} \\
\hline II (58) & 51 & 7 & \\
\hline III (II) & 10 & 1 & \\
\hline Previous SUI Surgery (I0) & 10 & 0 & $>0.05^{c}$ \\
\hline Associated POP Surgery (49) & 42 & 7 & $\mathrm{P}=0.230^{\circ}$ \\
\hline UDS Prior To Surgery (I I) & 10 & 1 & $P=0.804^{c}$ \\
\hline Immediate Complications (I0) & 8 & 2 & $P<0.05^{c}$ \\
\hline Intermediate Complications (3) & 3 & 0 & $\mathrm{P}<0.05^{c}$ \\
\hline Late Complications (II) & 4 & 7 & $P<0.05^{c}$ \\
\hline${ }^{a} U M W ;{ }^{b} T-S t u d e n t ;{ }^{c} C h i-s q u a r e$ & & & \\
\hline
\end{tabular}


There were also no differences in the degree of SUI and the frequency of complications between patients with and without recurrence of SUI (Table 2).

In this sample of patients, the immediate complications were $(\mathrm{n}=10)$ : fever, pain, bladder retention and urgent surgery for bleeding; as intermediate complications appeared $(\mathrm{n}=3)$ : urinary tract infection (UTI) and bladder retention, and after more than 1 month the complications were $(\mathrm{n}=11)$ : de novo urgency, bladder retention, pain and urethrolysis (Table 2).

The variables that showed a significant association with SUI recurrence in the bivariate analysis were: age, mixed urinary incontinence and fetal macrosomia.

As can be seen in the Figure 1, patients who presented SUI recurrence were older at the time of surgery (median of 75years) than those not presenting it (median of 67years). In addition, age as a predictor of recurrence has an area under the curve ROC of 0.79 .

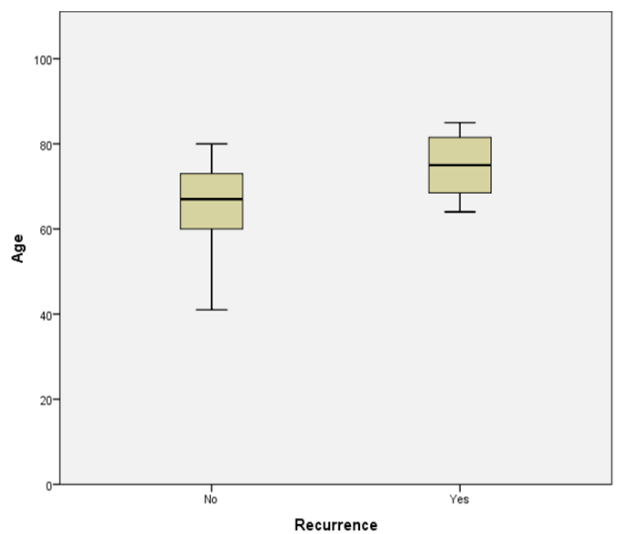

Figure I Age distribution in both groups

$22 \%$ of the patients with a history of fetal macrosomia who underwent surgery with a tension-free vaginal tape-obturator, presented recurrence of SUI after 4years and this percentage increased to $50 \%$ when they had 2 or more deliveries with fetus $>4 \mathrm{~kg}$ (Figure 2).

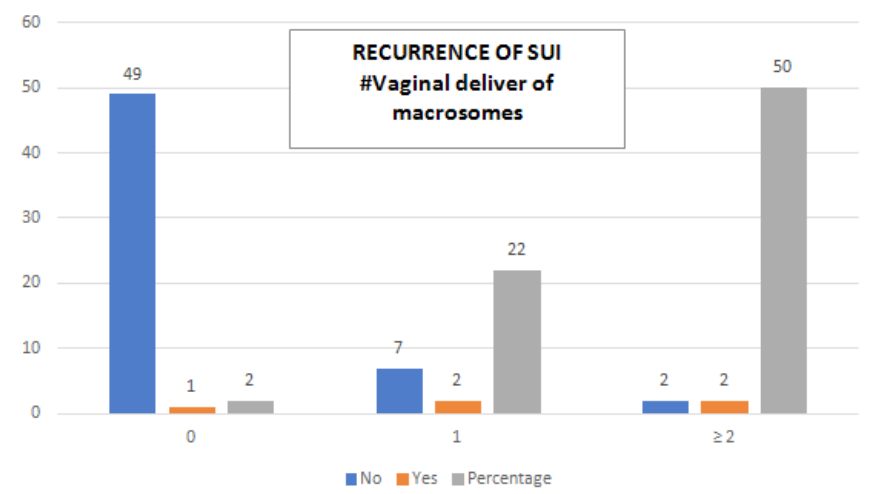

Figure 2 SUI recurrence if antecedent of delivery $>4 \mathrm{~kg}$ ( delivery $/ \geq 2$ deliveries).

The history of fetal macrosomia obtained an OR of 21.78 (95\% CI:2.18-218.03) for recurrence of SUI.

$19.5 \%$ of the women with MUI who underwent anti-incontinence surgery suffered a recurrence of SUI at the $4^{\text {th }}$ year, while patients with pure stress incontinence did not present it.
The probability of recurrence before surgery if having a MUI was $11.3 \%$, with $\mathrm{S}=100 \%, \mathrm{E}=47.6 \%$ and $\mathrm{FP}$ ratio $=52.4 \%$.

Bottom line: The frequency of recurrence of SUI at 4years was $11.27 \%$, but some factors increased this frequency, such as a history of fetal macrosomia ( 1 delivery $>4 \mathrm{~kg}: 22 \%$ and $\geq 2$ deliveries $>4 \mathrm{~kg}$ : $50 \%)$ and suffering MUI (19.5\%).

\section{Discussion}

Multiple variables have been evaluated and proposed as possible risk factors for the development of recurrence of SUI after tensionfree vaginal tape: advanced age, comorbidities, associated POP or concomitant POP surgery, a high BMI, presence of urgency or urge incontinence, previous urinary incontinence surgery, anticholinergic treatment or severity of incontinence.

Nevertheless, the advance in the knowledge of SUI recurrence after transobturator suburethral tape is complex for several reasons. The first is the heterogeneity of the available studies, from a methodological point of view and by the type of population included and the duration of follow-up. Most of the studies are retrospective and prospective, observational and cohort. Randomized controlled trials such as those of Barber, ${ }^{11}$ Angioli ${ }^{12}$ and Stav ${ }^{13}$ are rare. Furthermore, the follow-up years range from 1year, ${ }^{11,14,15} 4-5$ years,,$^{12,13,16-19}$ to $7-10$ years..$^{20-23}$

Our study is prospective observational, with a 4-year follow-up, and includes women with a prior MUI, a history of an anti-incontinence tape and POP surgery concomitant to the insertion of the tension-free vaginal tape. Therefore, it resembles the usual population, where all possible characteristics are given. Other studies have also included in their samples POP surgery, ${ }^{11,21}$ presenting an overactive bladder ${ }^{16,18,22}$ and having previously SUI surgery. ${ }^{14}$

There are authors who have carried out their studies with some exclusion criteria, which we have included such as associated POP surgery, ${ }^{16,23}$ overactive bladder ${ }^{11,23}$ and prior anti-incontinence tape. ${ }^{11}$

The frequency of recurrence of SUI at the $4^{\text {th }}$ year in our study was $11.27 \%$. This is similar to that found by other authors. Ashok, after a systematic review, describes it as $10-20 \%,{ }^{24}$ Yonsson Funk estimates it at $13 \%$ at 9 years ${ }^{20}$ and Serati at $9.2 \%$ at 5 years. ${ }^{17}$ Nevertheless, higher percentages have been reported: $16.5 \%$ at 1 year, ${ }^{11} 18 \%$ at 5 years ${ }^{16}$ and up to $30.12 \%$ at 4 years. ${ }^{19}$

In our population, the risk of recurrence of SUI at 4years was related to age, presenting MUI and a history of macrosomal delivery.

Thus, the frequency of recurrence if the type of incontinence was mixed amounted to $19.5 \%$, if the patient had 1 delivery $>4 \mathrm{~kg}$ to $22 \%$ and if the antecedent was $\geq 2$ macrosomal deliveries it increased up to $50 \%$.

In our sample, women who had recurrence were older than those who did not relapse (median of 75 vs 67 years). Other authors also agree with this association, such as Barber in his 1-year randomized study comparing retropubic versus transobturator tape,$^{11}$ and Jonnson Funk with a 9-year population analysis where he calculated the cumulative incidence of repeated surgery. ${ }^{20}$

However, other studies do not find this relationship, such as the 4-year Stav randomized study ${ }^{13}$ and the 4-year Betari retrospective study. ${ }^{19}$

As women get older, they lose the striated musculature of the bladder neck and dorsal wall of the urethra, ${ }^{25}$ which could modify the location of the suburethral sling and decrease its long-term efficacy. 
A randomized two-arm trial (transobturator tape, in-out vs outin) with 1-year follow-up, showed that for every 10 years that age increased, the risk of objective failure increased almost $50 \%$ compared to subjective. ${ }^{15}$ Objective measures are more related to the mechanism of action of the suburethral band, and this mechanism can be affected by varying the characteristics of adjacent tissues with advancing age. In contrast, subjective failures may be influenced by symptoms of urgency.

In the case of patients with MUI, we found a probability of recurrence before surgery of $11.3 \%$. No patient with pure SUI recurred during these 4years. Women with symptoms of urge incontinence may reflect more complex neuromuscular dysfunction, so perhaps in these patients, more intense treatment with lifestyle changes and/or medical therapies should be considered before surgery. ${ }^{15}$

A randomized study assigning 4-year retropubic or transobturator tape also related recurrence with MUI, with an OR of $2.4 .{ }^{13} \mathrm{~A}$ similar association with the MUI $(\mathrm{OR}=2.87)$ was found by Paick in a prospective cohort study (retropubic vs transobturator) but in the short term (mean follow-up of 10 months). ${ }^{26}$

The third significant association of our work was the history of macrosomal delivery, which obtained an OR of 21.78 (95\% CI:2.18218.03) for recurrence of SUI. This relationship has not been described in the literature and could suggest that women with births of more than $4 \mathrm{~kg}$ suffer greater involvement of the pelvic support structures, which in the long term would modify the positioning or function of the sling.

Several factors associated with recurrence described by other authors, such as prior anti-incontinence surgery, ${ }^{13,14,20}$ associated POP surgery ${ }^{11,27}$ or $\mathrm{BMI},{ }^{13}$ have not been related to the risk of recurrence in our sample.

\section{Conclusion}

Advanced age, a history of macrosomic delivery and presenting MUI have shown a significant association with the risk of relapse of SUI after tension-free vaginal tape-obturator at 4years.

This does not mean that these patients cannot benefit from the surgical treatment of the loss of urine with the effort, but that in the preoperative interview it would be necessary to inform them of a greater risk of failure in the medium term.

\section{Acknowledgments}

None.

\section{Author's contributions}

Each authors' contribution to the Manuscript:

S. De Miguel Manso, PhD: Project development, Data Collection, Manuscript writing.

E. García García, PhD: Data Collection, Manuscript writing.

J.A. Gobernado Tejedor, PhD, MD: Project development, Stadistical analisis.

C.E. Badillo Bercebal, PhD: Data Collection.

D. Viruega Cuaresma, PhD: Data Collection.

J.I. González Martín, PhD, MD: Data Collection.

\section{Funding}

No funding was obtained for the implementation of this study.

\section{Conflicts of interest}

The authors declare that they have no conflict of interest.

S. De Miguel Manso declares that she has no conflict of interest.

E. García García declares that she has no conflict of interest.

J.A. Gobernado Tejedor declares that he has no conflict of interest.

C.E. Badillo Bercebal declares that she has no conflict of interest.

D. Viruega Cuaresma declares that she has no conflict of interest.

J.I. González Martín declares that he has no conflict of interest.

\section{References}

1. Haylen BT, de Ridder D, Freeman RM, et al. An International Urogynecological Association (IUGA)/International Continence Society (ICS) joint report on the terminology for female pelvic floor dysfunction. Int Urogynecol J. 2010;29(1):4-20.

2. Capobianco G, Madonia M, Morelli S, et al. Management of female stress urinary incontinence: A care pathway and update. Maturitas. 2018;109:32-38.

3. Labrie J, Berghmans BL, Fischer K, et al. Surgery versus physiotherapy for stress urinary incontinence. Engl J Med. 2013;369(12):1124-1133.

4. European Association of Urology. EAU guidelines on urinary incontinence in adults. 2016.

5. Chapple CR, Cruz F, Deffieux X, et al. Consensus statement of the European urology association and the European urogynaecological association on the use of implanted materials for treating pelvic organ prolapse and stress urinary incontinence. Eur Urol. 2017;72(3):424-431.

6. Maggiore ULR, Agrò EF, Soligo M, et al. Long-term outcomes of TOT and TVT procedures for the treatment of female stress urinary incontinence: a systematic review and meta-analysis. Int Urogynecol J. 2017;28(8):11191130.

7. Karmakar D, Mostafa A, Abdel-Fattah M. Long-term outcomes of transobturator tapes in women with stress urinary incontinence: E-TOT randomised controlled trial. BJOG. 2017;124(6):973-981.

8. Maturana P, Palos CC, Ghersel FR, et al. Randomized controlled trial comparing mini-sling with transobturator sling for the treatment of stress urinary incontinence. Int Urogynecol J. 2019.

9. Nambiar A, Cody JD, Jeffery ET, et al. Single-incision sling operations for urinary incontinence in women. Cochrane Database Syst Rev. 2017;7(7):CD008709.

10. Ford AA, Rogerson L, Cody JD, et al. Mid-urethral sling operations for stress urinary incontinence in women. Cochrane Database Syst Rev. 2017;7(7):CD006375.

11. Barber MD, Kleeman S, Karram MM, et al. Risk factors associated with failure 1 year after retropubic or transobturator midurethral slings. $\mathrm{Am} J$ Obstet Gynecol. 2008;199(6):666.e1-7.

12. Angioli R, Plotti F, Muzii L, et al. Tension-free vaginal tape versus transobturator suburethral tape: five-year follow-up results of a prospective, randomised trial. Eur Urol. 2010;58(5):671-677.

13. Stav K, Dwyer PL, Rosamilia A, et al. Risk factors of treatment failure of midurethral sling procedures for women with urinary stress incontinence. Int Urogynecol J. 2010;21(2):149-155. 
14. Abdel-Fattah M, Ramsay I, Pringle S, et al. Evaluation of transobturator tension-free vaginal tapes in management of women with recurrent stress urinary incontinence. Urology. 2011;77(5):1070-1075.

15. Richter HE, Heather JL, Emily SL, et al, Urinary Incontinence Treatmen Network. Demographic and clinical predictors of treatment failure one year after midurethral sling surgery. Obstet Gynecol. 2011;117(4):913921.

16. Groutz A, Rosen G, Gold R, et al. Long-term outcome of transobturato tension-free vaginal tape: efficacy and risk factors for surgical failure. $J$ Womens Health. 2011;20(10):1525-1528.

17. Serati M, Bauer R, Cornu JN, et al. TVT-O for the treatment of pure urodynamic stress incontinence: efficacy, adverse effects, and prognostic factors at 5-year follow-up. Eur Urol. 2013;63(5):872-878.

18. Yonguc T, Gunlusoy B, Degirmenci T, et al. Are the outcomes of transobturator tape procedure for female stress urinary incontinence durable in long-term follow-up? Int Urol Nephrol. 2014;46(7):1295-1300.

19. Betari R, Meynier J, Forzini T, et al. Is initial success after monarc( $(\mathbb{R})$ suburethral sling durable at mid-term evaluation? Prog Urol. 2016;26(7):409-414.

20. Jonsson Funk M, Siddiqui NY, Kawasaki A, et al. Long-term outcome after stress urinary incontinence surgery. Obstet Gynecol. 2012;120(1):8390.
21. Athanasiou S, Grigoriadis T, Zacharakis D, et al. Seven years of objective and subjective outcomes of transobturator (TVT-O) vaginal tape: why do tapes fail? Int Urogynecol J. 2014;25(2):219-225.

22. Costantini E, Kocjancic E, Lazzeri M, et al. Long-term efficacy of the trans-obturator and retropubic mid-urethral slings for stress urinary incontinence: update from a randomized clinical trial. World $\mathrm{J}$ Urol. 2016;34(4):585-593.

23. Serati M, Braga A, Athanasiou S, et al. Tension-free vaginal tape-obturator for treatment of pure urodynamic stress urinary incontinence: efficacy and adverse effects at 10-year follow-up. Eur Urol. 2017;71(4):674-679.

24. Ashok K, Wang A. Recurrent urinary stress incontinence: an overview. $J$ Obstet Gynaecol Res. 2010;36(3):467-473.

25. Perucchini D, DeLancey JOL, Ashton-Miller JA, et al. Age effects on urethral striated muscle. II. Anatomic location of muscle loss. Am J Obstet Gynecol. 2002;186(3):356-360.

26. Paick JS, Cho MC, Oh SJ, et al. Factors influencing the outcome of mid urethral sling procedures for female urinary incontinence. $J$ Urol. 2007;178(3 Pt 1):985-989.

27. Black NA, Downs SH. The effectiveness of surgery for stress incontinence in women: a systematic review. Br J Urol.1996;78(4):497-510. 